\title{
FDI and Economic Growth in Western Region of China and Dynamic Mechanism: Based on Time-Series Data from 1986 to 2010
}

\author{
Lina $\operatorname{Lian}^{1} \&$ Haiying $\mathrm{Ma}^{1}$ \\ ${ }^{1}$ School of Economics, Northwest University for Nationalities, Lanzhou, P. R. China \\ Correspondence: Lina Lian, School of Economics, Northwest University for Nationalities, Lanzhou 730124, P. \\ R. China. E-mail: 1lnhappy2010@126.com
}

Received: December 14, 2012

Accepted: February 2, 2013

Online Published: March 20, 2013

doi:10.5539/ibr.v6n4p180

URL: http://dx.doi.org/10.5539/ibr.v6n4p180

This work was supported by the Fundamental Research Funds for the Central Universities of Northwest University for Nationalities China under grants ZYZ2012010.

\begin{abstract}
In this paper, we analyze causal relationship between foreign direct investment (FDI) and economic growth in western region of China using time-series data from 1986-2010. The analysis is conducted by the means of time-series estimations through ADF unit root test, co-integration tests, error-correction analysis and Granger causality test. The purpose of the paper is to empirically investigate the impact of economic growth on FDI in western region and its dynamical mechanism. The results suggest that inward FDI flow does not lead to Granger-cause economic growth, and economic growth also does not exert significant impacts on FDI inflows, which means some studies have exaggerated the positive effect of FDI on economic growth, and eclipsed the influence of economic growth on FDI.
\end{abstract}

Keywords: FDI, economic growth, error-correction analysis, Granger causality test

\section{Introduction}

The correlation between foreign direct investment (FDI) and economic growth has been the key topics of researchers, government officials and practitioners for decades. There have been vast numbers of empirical research to examine the impact of FDI on the economic growth of different recipient countries. However, there is no consensus on the relationship between FDI and economic growth, some researchers and practitioners suggest that FDI are positively related to economic growth (Caves, 1974; Globerman, 1979; Li \& Liu, 2005), while others disclosed the truth as contradictory as negative connections (Grilli \& Milesi-Ferretti, 1995; Borensztein \& Lee, 1998). As concluded in some research papers that it is possible that both FDI and economic growth are interdependent and may lead to two way causality (Zhang, 2001). Thus, we may sum up that the relationship between FDI and economic growth is not so definitely defined, and even studies examining one specific growth-enhancing factors of FDI (i.e. knowledge spillovers, technology spillovers, productivity initiatives in social dimensions, transparent and predictable regulatory and policy framework, technology diffusion, acquisition of product and process innovation, better management practice, commercialization of advanced technologies etc.) show the paradoxical conclusions in their findings. Blonigen and Wang (2005) illustrate the importance of distinguishing the developed countries and the developing countries, thus make the FDI contributions clear-cut as in two differentiated cases. Simultaneously, other scholars are trying to analyze the endogeneity problem between FDI and economic growth by many empirical means and methods (Li \& Liu, 2005; Chowdury \& Mavrotas, 2006), such as Granger causality or VAR/VECM frameworks (Burham, 2004) or the Arrelano-Bond generalized method of moments (GMM) approach (Yao, 2006). In China, an increasing number of studies attempted to reveal the uneven regional allotment of FDI and its contributing factors. Wei (2002) studied the great FDI disparity between coastal and inland regions. Li (2004) proved the differentiated FDI spur among three regions as eastern, mid and western regions of China. Since "go west" policy, the growing FDI inflows into western region has become an important driving force of ecnomy development. However, there are few studies providing the causal relationships between FDI and economic growth, especially in less-developed western region with large number of minorities' population. 
The objective of this paper is to examine the causal relationships between FDI and economic growth in western region of China and to figure out the correlated dynamical mechanism. The first section of the study encompasses a brief introduction. Section Two presents data and methodology employed in great details. Section Three examines empirical analysis and findings of causal relationships between FDI and economic growth. The last section sketches the conclusions and some reflections as to further the FDI attraction yet tailed to the local economy development agenda.

\section{Theoretical Basis}

The concept of "investment led economic development" has promoted the idea that the outward or inward FDI position of a country is linked to its economic development relative to the rest of the world. As the ultimate goal of multinational corporations is to maximize their profit, the foreign direct investment is the effective channels for them to achieve maximum returns. Most importantly, the FDI inflows comprise capital provided by foreign donators, directly or indirectly to fulfill some collaborative expectations in stimulating the economies of the host countries as in the ways of promoting market integration, participating in the management of recipient enterprises, establishing marketing and procuring networks for efficient production and sales internationally, and exercising as strong backbones for the money injections of the economy appetites. There is a long list of fruitful theory conclusions that hints that, to some degree, FDI is a significant engine for economic growth, or at least it is one of the indispensable factors to the economy advancement of a specific country or region. Hymer compares the direct and portfolio investment thus to explain the motions for firms to exercise their controls over the foreign partners. He concludes that if the markets are imperfect and there is horizontal or bilateral monopoly or oligopoly, some form of collusion will be profitable. Vernon first proposes the Product Life Cycle theory. Then Coase advances the Theory of Internalization in domestic context and Hymer portrays something new in an international dimension. Dunning puts forward the Eclectic Theory of International Production on the base of conventional international trade theory. He argues that whether the international investment may happen should be determined by the following three advantages as the Ownership Specific Advantage, Internalization Advantage and the Location Specific Advantage.

\section{Date and Methodology}

In this paper, $F D I$ is measured as the amount of foreign capital actually utilized and economic growth is measured as real GDP. The relationship between GDP and FDI of western region (inclusive of Sichuan, Yunnan, Guangxi, Guizhou, Qinghai, Ningxia, Gansu, Inter-Mongolia, Shanxi, Xinjiang and Chongqing, and Tibet is not included for lack of the data in the initial period of the research period) is examined on the basis of annual time series data for the period of 1986-2010. All the data used in this paper are obtained from China Statistics Yearbook 1987-2011. To achieve consistency, data reported in RMB are converted into USD dollars based on the current year average market exchange rates, which are produced by National Bureau of Statistics in China. For testing purpose, all time-series are expressed in real terms using a GDP deflator (1978=100) and in natural logarithms.

In order to make the following analysis perceptible and accurate enough, all variables in a regression model must be stationary or co-integrated. Therefore, the first phase of the study is that unit root tests are performed on the time series to investigate stationarity on both GDP and FDI. According to Engle and Granger (Dickey \& Fuller, 1979), if two variables are integrated of order one, 1 (1), and are co-integrated, then either unitary-directional or bi-directional Granger causality must exist in the $1(0)$ variables once the two series satisfy the unit root properties. The paper carries out the co-integration test in order to empirically check whether there exists a cause-and-effect relationship between $G D P$ and $F D I$ in western region of China. If the two series of variables are found to be co-integrated, then we take remedies to lessen the error correction term from the co-integrating equation and investigate the direction of causation. Yet if it is the other case, then we employ Granger's causality to test the direction of short-run causation.

\section{Empirical Analysis and Findings-Examination of the Relationship between FDI and Economic Growth of the Western Region China}

\subsection{Unit Root Test}

The augmented Dickey-Fuller test (ADF) (Dickey \& Fuller, 1979) is a test for a unit root in a time series sample. It's a larger and more complicated set of time series models, and it indicates the error term is not white noise. As can be seen from Fig. 1, both the series appears to be non-stationary in level form, therefore, we investigate the stationarity of the first difference of the series by testing for unit roots. It could be divided into three main versions which may be stated as follows: 
Non-constancy and non-trend model:

$$
\Delta y_{t}=w y_{t-1}+\sum_{i=1}^{k} \beta_{i} \Delta y_{t-i}+\varepsilon_{t}
$$

Constancy and non-trend model:

Constancy and trend model:

$$
\Delta y_{t}=\alpha_{0}+\omega y_{t-1}+\sum_{i=1}^{k} \beta_{i} \Delta y_{t-i+1}+\varepsilon_{t}
$$

$$
\Delta y_{t}=\alpha_{0}+\alpha_{1} t+\omega y_{t-1}+\sum_{i=1}^{w} \beta_{i} \Delta y_{t-i+1}+\varepsilon_{t}
$$

Where $\Delta$ means first difference, $y_{t}$ is predictor variable, $\alpha$ is the intercept. $\omega$ stands for auto-regression term, $\alpha_{1} t$ is the time trend term and $\sum_{i=1}^{w} \beta_{i} \Delta y_{t-i+1}$ refers to lag term of dependent variables, $\varepsilon_{t}$ represents the error term.

The hypothesis of unit root is: $\mathrm{H}_{0}: \mathrm{w}=0$ and $\mathrm{H}_{1}: \mathrm{w} \neq 0$

If the null hypothesis $\left(\mathrm{H}_{0}\right)$ is rejected, it concludes to reject the variables existing the unit root. Thus, the predictor variable will be the stationary time series.

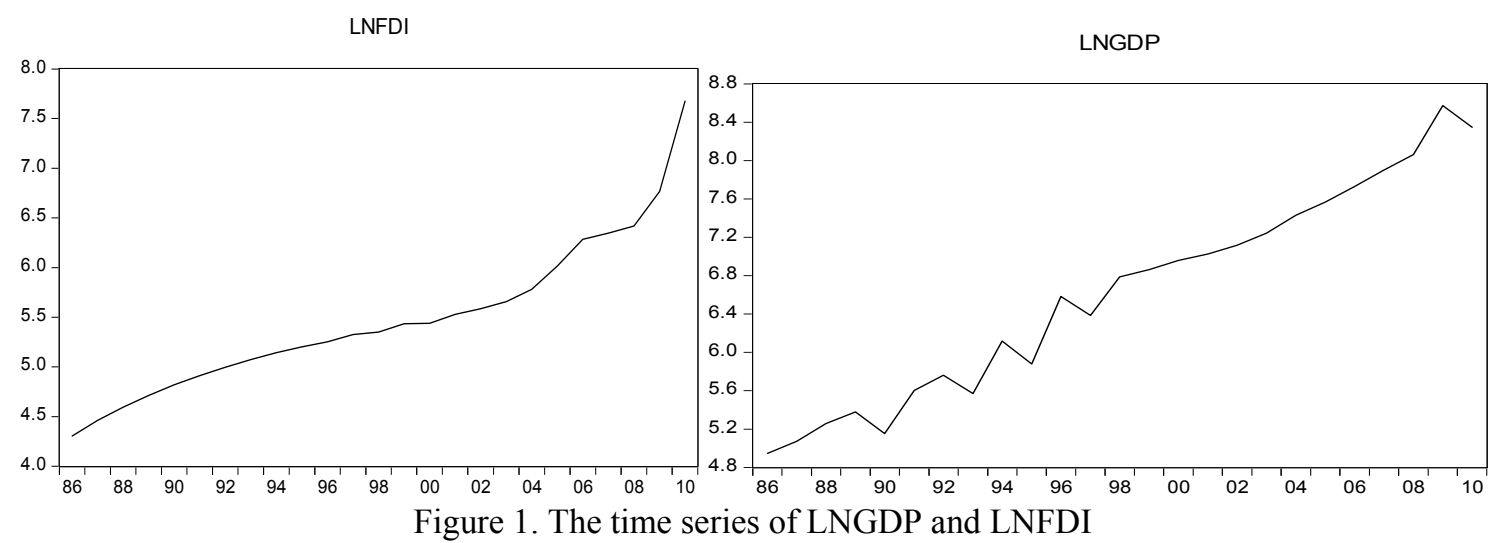

Table 1 is the results of the ADF test, and it shows that the null hypothesis of a unit root is (a) accepted for the level series of GDP in three models. (b) rejected for the level series of FDI in the model (2), and (c) rejected for all the first differenced series (except $G D P$ in model 1). Therefore the null hypothesis of non-stationary could not be rejected, and both of the series are stationary. We can say that both times series are integrated of

\begin{tabular}{|c|c|c|c|}
\hline \multirow{2}{*}{ Variables } & Model (1) & Model (2) & Model (3) \\
\hline & Non-constancy\& Non-trend & Constancy \& Non-trend & Constancy \& Non-trend \\
\hline \multicolumn{4}{|c|}{ 1. ADF test for unit root on the level series } \\
\hline$G D P$ & 4.5754 & 4.3452 & 0.4812 \\
\hline FDI & 0.8267 & $-3.7441 *$ & -2.9311 \\
\hline \multicolumn{4}{|c|}{ 2. ADF test for unit root on the first difference series } \\
\hline$G D P$ & 0.9357 & $-4.2889 *$ & $-6.3612 *$ \\
\hline$F D I$ & $-5.777 *$ & $-6.4572 *$ & $-6.4247 *$ \\
\hline
\end{tabular}
order 1, 1(1).

Table 1. Results of ADF unit root test

Notes: * denotes significance at the $1 \%$ level.

\subsection{Co-Integration Test}

Since all the data series are integrated processes of order 1 (1), the co-integration test will be performed to check the equilibrium relationship between the two variables of $G D P$ and $F D I$. The co-integration test applies the 
best method of co-integration log likelihood ratio (LR) brought forward by Johanson. The results is outlined in table 2, which provides evidence to reject the null of zero co-integrating vectors in favour of one co- integrating vector at the $1 \%$ level of significance. The results suggest that there should be a long equilibrium relationship between $G D P$ and FDI in western region of China.

Table 2. Results of Johansen co-integration test

\begin{tabular}{llllll}
\hline H0:rank=i & Eigenvalue & Likelihood Ratio Test & $5 \%$ Critical Value & $1 \%$ Critical Value & No. of CE(s) \\
\hline Rank $=0$ & 0.5812 & 24.0866 & 15,41 & 20.04 & None * \\
Rank $\leq 1$ & 0.0573 & 1.5345 & 3.76 & 6.65 & At most 1 \\
\hline
\end{tabular}

Notes: $*$ denotes rejection of the null hypothesis at the $1 \%$ level of significance.

\subsection{The Error Correction Model}

Engle and Granger show that if non-stationary variables are co-integrated, then a vector autoregression (VAR) in the first differences is miss-specified. Since a co-integration relationship is evidenced between GDP and $F D I$, an error correction model (ECM) is employed to test the intemperate causality between these two variables. Table 3 portrays the results of the error correction models.

Table 3. The results of the estimation of error correction model

\begin{tabular}{lll}
\hline Variables & $\Delta G D P_{t}$ & $\Delta F D I_{t}$ \\
\hline$\Delta G D P_{t-1}$ & $/$ & $\begin{array}{l}0.7459 * \\
(2.7223)\end{array}$ \\
\hline$\Delta F D I_{t-1}$ & -0.0094 & $/$ \\
\hline \multirow{2}{*}{$\mathrm{VECM}_{\mathrm{t}-1}$} & $(-0.1336)$ & $-0.1320 *$ \\
& -0.0102 & $(-2.5625)$ \\
\hline
\end{tabular}

Notes: figures in parentheses are t statistics; $*$ denotes significance at the $1 \%$ level.

As shown in the table 3, the estimation coefficient of the interpretive variable $\triangle F D I_{t-1}$ in the $\triangle G D P$ equation indicates that FDI reduces $G D P$, however, the $p$ value of null hypothesis of the Wald test statistics is -0.1336 , which shows that the estimation value is beyond statistical significance. The next step of the test is to find out whether the error correction coefficient or co-integration coefficient is zero. Though the error correction coefficient of the $\triangle G D P$ equation is -0.0102 , the $p$ value of the null hypothesis of the Wald test statistic is -0.7368 , which indicates that the significance in statistic terms is null. As a result, the assumption that $F D I$ impels $G D P$ is false.

The same method is applicable to testing whether the economic development of western region attracts the inward FDI flows. First of all, the estimation coefficient of $\triangle F D I$ affected by $\triangle F D I_{t-1}$ tells that the economic development of western region stimulates $F D I$ inflows, the $p$ value of the null hypothesis of Wald test statistics is 2.7223 , indicating that the assumption in statistics terms is significant. The $p$ value of the null hypothesis with further application of the Wald test is -2.5625 and the significance in statistics terms in not null. The test results support the hypothesis that the economic development of western region draws the FDI inflows.

\subsection{The Granger Causality Test}

If the variables are non-stationary and co-integrated, we may use the Vector Error Correction Model (VECM) to examine the causal relations between the concerned variables (Granger, 1988). Yet if it is in the case of no co-integration found among the variables, a VAR model is used.

The results of the GC test are shown in Table 4. They announce that a zero hypothesis that economic development does not exert effects on FDI can be rejected, and which further implies the opposite hypothesis, i.e., economic growth may affect $F D I$ inflows. Similarly, a non-rejection of the zero hypotheses that FDI does not have impacts on economic growth implies that the opposite hypothesis that FDI affects economic growth is not rationalized as well. In brief, the two differentiated cases cannot be proved true simultaneously. If the hypothesis that economic growth draws inward FDI flows is evidenced firm, the reverse causality, i.e. that $F D I$ has influences on economic growth, shall definitely be rejected. 
Table 4. Granger causality test

\begin{tabular}{llll}
\hline Null hypothesis & Observations & F-Statistics & Probability \\
\hline & 23 & & \\
$F D I$ does not affect $G D P$ & & 1.43844 & 0.3421 \\
$G D P$ does not addect $F D I$ & & 5.68432 & $0.0352 *$ \\
\hline
\end{tabular}

Notes: $*$ denotes significance at the $5 \%$ level.

\subsection{Findings}

Since economic growth in western region affects FDI in the light of above analysis, we can establish the following equation:

$$
L N F D I=\alpha+\beta L N G D P
$$

Above Equation is estimated by pooled ordinary least square (Pooled OLS), and the results are shown by E-view6.0 as follows:

$$
L N F D I=1.649+0.571 L N G D P \quad R^{2}=0.936 \quad F=305.995 \quad D W=1.021
$$

It alleges that economic advancement has exerted a positive influence on $F D I$, that is, while GDP increases at the rate of $1 \%, F D I$ will increase by $0.57 \%$.

\subsection{Dynamic Mechanism of FDI and GDP in Western Region China}

As we discussed that $F D I$ promote economic growth in western region in certain extents. Now we attempt to build up a dynamical system between $F D I$ and $G D P$ for western region in order to investigate dynamical mechanism of the two variables.

$$
\left\{\begin{array}{l}
\frac{d G D P}{d t}=a G D P+b F D I+c G D P \cdot F D I \\
\frac{d F D I}{d t}=d G D P+e F D I+f G D P \cdot F D I
\end{array}\right.
$$

In above dynamical model, $a, b, c, d, e, f$ are coefficients. If $b, c, e, f$ are zeros, $a, b$ are greater than zeros. It means $F D I$ and $G D P$ in western region are two independent system with self-growth dynamic mechanism. The model can be solved to: $E_{0}=(0,0)$ and $E_{1}=\left(G D P^{*}, F D I^{*}\right)$, and where

$$
\left\{\begin{array}{l}
G D P^{*}=\frac{b d-a e}{f a-d c} \\
F D I^{*}=\frac{a e-b d}{b f-c e}
\end{array}\right.
$$

It is obvious that $E_{0}=(0,0)$ is non-sense, $E_{1}=\left(G D P^{*}, F D I^{*}\right)$ will be significant if and only if $a / b>d / e$, $f / e>c / d$.

Based on time-series data from 1986-2010 of FDI and GDP, we can have dynamic model for $F D I$ and $G D P$ in western region China as follows:

$$
\left\{\begin{array}{l}
\frac{d G D P}{d t}=0.0929 G D P+15.111 F D I-1.067 \times 10^{-3} G D P \cdot F D I+[A R(2)=-0.8567] \\
\frac{d F D I}{d t}=0.6421 G D P-4.55 \times 10^{-5} G D P \cdot F D I
\end{array}\right.
$$

In Equ.6, F-statistics and DW value passed tests, the $\mathrm{t}$ value of all the variables including non-linear are significant with $5 \%$ level. The adjusted $R^{2}$ is above 55\% indicating better goodness to fit. (see table 5) Time variable does not appear in the above-mentioned model, it means FDI and GDP system has nothing related to the time span. Therefore, $F D I$ and $G D P$ dynamic system in western region China is a self-governing non-linear mechanic system. 
Table 5. Test results of dynamic model of $F D I$ and GDP in western region China

\begin{tabular}{llll}
\hline & Adj. $R^{2}$ & $D W$ & min value of $|t|$ \\
\hline$d G D P / d t$ & 0.7512 & 1.7025 & 2.2141 \\
\hline$d F D I / d t$ & 0.5491 & 2.2851 & 2.908 \\
\hline
\end{tabular}

Eq. 6 implies that $F D I$ and $G D P$ in western region is characterized by interactive mechanism of self-growth and constrained by coupling influence. That is to say, FDI does not lead to Granger-cause economic growth, and economic growth also does not significantly affect $F D I$.

\section{Conclusions and Reflections}

This paper has analyzed the linkage between GDP and FDI in western region China, exemplified by time-series data through $\mathrm{ADF}$ unit root tests, co-integration tests, error-correction analysis and Granger causality test. The results show that FDI inflows of western region China does not lead to Granger-cause economic growth, and economic growth also does not , significantly affect FDI. This finding alleges that some researchers, in their publication papers, have exaggerated the practical effect of FDI on economic growth, and underestimated the impacts of economic growth on FDI. On one hand, the result that the economic growth attracts FDI demonstrates the validity of "market-size hypothesis", which emphasizes the importance of growing market size, and the penetration of foreign markets is a major motive for FDI. On the other hand, the empirical finding that FDI does not promote economic growth implies that FDI may have crowded out domestic investment, rather than have been a complementary relationship with domestic investment, which has partly offset the influence of investment on economic growth in the host country. Based on the finding in this paper, we may draw some conclusions related to policy implications for western region China. The result suggest that host government should not only encourage FDI inflows, but also should take measures to improve the quality of utilizing FDI, so as to achieve the goal of promoting economic growth as far as possible. In addition, the result indicates that an equal competing environment should be provided for FDI and domestic investment, to enhance the combined effect of investment on economic growth.

\section{References}

Blonigen, B. A., \& Wang, M. (2005). Inappropriate pooling of wealthy and poor countries in empirical FDI studies. In T. Moran, M. Graham, \& M. Blomstrom (Eds.), Does Foreign Direct Investment promote development? (pp. 221-243). Washington, DC: Institute for International Economics.

Borensztein, E., DeGregorio, J., \& Lee, J. W. (1998). How does foreign direct investment affect economic $\begin{array}{lllll}\text { growth? Journal of International } & \text { Economics, } & \text { 45(1), }\end{array}$ http://dx.doi.org/10.1016/S0022-1996(97)00033-0

Caves, R. (1974). Multinational firms, competition and productivity in host country markets. Economica, 41, 176-193. http://dx.doi.org/10.2307/2553765

Chowdury, A., \& Mavrotas, G. (2006). FDI and growth: What causes what? World Economy, 29(1), 9-19. http://dx.doi.org/10.1111/j.1467-9701.2006.00755.x

Dickey, D. A., \& Fuller, W. A. (1979). Distribution of Estimators for Time Series Regressions with a Unit Roots. Journal of the American Statistical Association, 74, 427-431.

Durham, J. B. J. (2004). Absorptive capacity and the effects of foreign direct investment and equity foreign portfolio investment on economic growth. European Economic Review, 48(2), 285-306. http://dx.doi.org/10.1016/S0014-2921(02)00264-7

Globerman, S. (1979). Foreign Direct Investment and spillover efficiency benefits in Canadian manufacturing Industries. Canadian Journal of Economics, 12, 42-56. http://dx.doi.org/10.2307/134570

Granger, C. W. J. (1969). Investigating Causal Relations by Econometric Models and Cross-Spectral Methods. Econometrica, 37, 24-36. http://dx.doi.org/10.2307/1912791

Granger, C. W. J. (1988). Some Recent Developments in a Concept of Causality. Journal of Econometrics, 39, 199-211. http://dx.doi.org/10.1016/0304-4076(88)90045-0

Grilli, V., \& Milesi-Ferretti, G. M. (1995). Economic Effects and Structural Determinants of Capital Control. IMF Staff Papers, 42, 517-551. http://dx.doi.org/10.2307/3867531

Li, X. (2004). Regional distribution change of FDI in China and the problems of promoting its inflow to inland. Economic Geography, 24, 304-308 (in Chinese). 
Li, X., \& Liu, X. (2005). Foreign Direct Investment and economic growth: An increasingly endogenous relationship. World Development, 3, 393-407. http://dx.doi.org/10.1016/j.worlddev.2004.11.001

Wei, H. (2002). The effect of FDI on regional economic development of China. Economic Research, 4, 19-26 (in Chinese).

Yao, S. J. (2006). On economic growth, FDI and exports in China. Applied Economics, 38(3), 339-351. http://dx.doi.org/10.1080/00036840500368730

Zhang, K. H. (2001). Does Foreign Direct Investment Promote Economic Growth? Evidences from East Asia and Latin America. Comtemporary Economics Policy, 19(2), 175-185. http://dx.doi.org/10.1111/j.1465-7287.2001.tb00059.x 